\title{
Bond and Stock Returns in a Simple Exchange Model
}

\section{Citation}

Campbell, John Y. 1986. Bond and stock returns in a simple exchange model. Quarterly Journal of Economics 101(4): 785-803.

\section{Published Version}

http://dx.doi.org/10.2307/1884178

\section{Permanent link}

http://nrs.harvard.edu/urn-3:HUL.InstRepos:3122544

\section{Terms of Use}

This article was downloaded from Harvard University's DASH repository, and is made available under the terms and conditions applicable to Other Posted Material, as set forth at http:// nrs.harvard.edu/urn-3:HUL.InstRepos:dash.current.terms-of-use\#LAA

\section{Share Your Story}

The Harvard community has made this article openly available.

Please share how this access benefits you. Submit a story.

\section{Accessibility}




\title{
BOND AND STOCK RETURNS IN A SIMPLE EXCHANGE MODEL*
}

\author{
JOHN Y. CAMPBELL
}

This paper studies asset pricing in a general equilibrium representative agent exchange model. The assumptions of isoelastic period utility and lognormal endowment allow the derivation of closed-form solutions for asset returns without restricting the serial correlation of the log endowment. Risk premiums on stocks and real bonds are found to be simple functions of relative risk aversion, the variance of the log endowment innovation, and the weights in the moving average representation of the log endowment. The paper analyzes the sign of term premiums, the size of the equity premium, and the effect of taste shocks on asset prices.

Some long-standing puzzles in economics concern the relationship between bond and stock returns and the macroeconomy. What forces determine expected excess returns on long bonds over short bonds? Is there any presumption that such term premiums tend to be positive, negative, or zero? Why are common stock returns so much higher on average than returns on short-term assets?

In this paper I use a "representative agent" model of general equilibrium to approach such questions. ${ }^{1}$ The model aggregates heterogeneous agents and prices assets from the first-order conditions of a representative agent's intertemporal optimization problem. The formal conditions for this to be valid are restrictive, but the results elucidate fundamental forces that one would expect to be at work in the actual economy.

I measure all quantities and prices in real terms, and study assets with real payoffs. Presumably the same forces operate in a monetary economy, but I do not attempt to analyze monetary factors here.

The model is set in discrete time. It provides closed-form solutions for asset prices and returns as functions of current, past,

*I am grateful to Olivier Blanchard, Steve Cecchetti, Rich Clarida, Ian Jewitt, Steve LeRoy, Greg Mankiw, Jim Poterba, Matthew Shapiro, Kim Schoenholtz, Bob Shiller, Larry Summers, James Tobin, Ken West, and Susan Woodward; and seminar participants at the National Bureau, Princeton, M.I.T., and Wharton for helpful comments on earlier versions of this paper.

1. This type of model has recently been popular; applications to asset pricing include Breeden [1979, 1986], Hansen and Singleton [1982, 1983], Grossman and Shiller [1981], Lucas [1978, 1982], LeRoy [1982], Donaldson and Mehra [1984], Mehra and Prescott [1985], Michener [1982, 1984], and Cox, Ingersoll, and Ross [1985].

(C) 1986 by the President and Fellows of Harvard College. Published by John Wiley \& Sons, Inc. The Quarterly Journal of Economics, November 1986

CCC 0033-5533/86/040785-19\$04.00 
and future consumption levels. Since consumption levels are treated as given, it is easiest to think of the model as an exchange model in which the representative agent consumes a nonstorable endowment each period, and all assets are in zero net supply. This interpretation is required for comparative static exercises in which I discuss the effects of changing the time series behavior of consumption, while holding fixed the other parameters of the model.

It is important to note, however, that the asset pricing formulas are also valid for assets in positive net supply in a production economy; for example, they apply to the model of Michener [1984]. In such an economy the existence of investment possibilities affects the equilibrium, but given equilibrium consumption levels, investment opportunities and assets that are in zero net supply can both be priced using the methods of this paper.

The model remains highly special in some dimensions-notably the utility function of the representative agent and the distribution of shocks to the economy-but it allows a very general specification of the time series behavior of consumption. Consumption is assumed to follow a univariate stochastic process, which must be stationary in either log levels or log first differences, ${ }^{2}$ but is otherwise unrestricted. The key contribution of the paper is to use the moving average representation of univariate stationary processes to characterize asset prices. The generalization to multivariate processes is straightforward, but is omitted here for reasons of space.

It is worth clarifying the relationship between this approach and that of previous work. The existence proofs of Lucas [1978], Donaldson and Mehra [1984], and others apply to models in which the state of the economy evolves according to a vector Markov process. In general, such processes have $K$ state variables and $K$ independent shocks or sources of uncertainty. This formulation is too general to yield closed forms without further restrictions, so authors such as LeRoy [1982], Michener [1982], and Mehra and Prescott [1985] have analyzed exchange models in which the endowment follows a univariate Markov process. Here there is one state variable and one source of uncertainty.

The univariate stationary processes considered here can be thought of as special vector Markov processes in which there is only one source of uncertainty, but there can be many state vari-

2. Nelson and Plosser [1982] offer evidence that many macroeconomic variables are well modeled as stationary in log first differences. 
ables. Each state variable is a linear combination of lagged values of consumption, and is updated each period using current and lagged innovations in consumption. ${ }^{3}$

The number of sources of uncertainty is also the number of independent assets that are required to hedge aggregate risk in the economy. Thus, when consumption follows a univariate process, the one-period returns on all the assets priced in this paper are perfectly correlated, even though there may be many state variables. Despite this low dimensionality of the asset return space, the derivation of expected returns on different assets is not trivial and has considerable economic interest.

In the first section of this paper, I lay out the assumptions of the model formally. I then study various applications, including the sign and magnitude of risk premiums in a term structure of real bonds (Section II); risk premiums on equity (Section III); and the effect on asset pricing of random shocks in the utility function (Section IV). In Section V, I summarize the results.

\section{Assumptions}

The first assumption of the model concerns the representative agent's utility function. This is assumed to be time separable with isoelastic period utility; it has two free parameters: $\alpha$ the coefficient of relative risk aversion, and $\beta$ the discount factor. ${ }^{4}$ In Section IV the utility function is extended to include multiplicative "taste shocks"; for the present, I simply write the representative agent's problem as

$$
\max E_{t} \sum_{k=0}^{\infty} \beta^{k} u\left(c_{t+k}\right)=E_{t} \sum_{k=0}^{\infty} \frac{\beta^{k} c_{t+k}^{1-\alpha}}{1-\alpha} .
$$

The second assumption of the model is that future levels of the representative agent's endowment are distributed lognormally conditional on the agent's current information.

3. Cox, Ingersoll, and Ross [1981] discuss Markov processes of this type in a continuous time setting.

4. This utility function is one of the simplest members of a class characterized by Eichenbaum, Hansen, and Richard [1984], which allows aggregation over heterogeneous consumers under certain rather special circumstances. Heterogeneity here means that individual consumers have different endowments and may have individual "taste shocks" to their utility functions. Aggregation is possible when the consumers have common information, common parameters $\alpha$ and $\beta$, and operate in a complete markets setting. 
The third assumption is that the log of the endowment can be characterized by one of the following two statements:

(a) The log endowment follows a univariate, stationary, invertible stochastic process about a deterministic trend. (For expositional convenience I shall assume that the trend is linear.) By Wold's Decomposition Theorem, one can write a unique invertible moving average representation of the log endowment, which in equilibrium equals $\log c_{t}$, as

$$
\log c_{t}=g t+\xi(L) e_{t}=g t+\sum_{k=0}^{\infty} \xi_{k} e_{t-k},
$$

where $L$ is the lag operator and $\xi_{0}$ is normalized to equal one. Assumption 2 of the model requires that the innovation $e_{t}$ be normally distributed; I assume that it is i.i.d. with mean zero and standard deviation $s_{e}{ }^{5}$

Stationarity and invertibility impose restrictions on the sum of squares of $\xi_{i}$ and the sum of $\xi_{i}$, respectively. For stationarity, one must have

$$
\sum_{k=0}^{\infty} \xi_{k}^{2}<\infty
$$

a condition that guarantees that the variance of $\log c_{t}$ is finite, and by the Cauchy-Schwartz Inequality, that all its autocovariances are finite. From the finite sum of squares, it follows that

$$
\lim _{i \rightarrow \infty} \xi_{i}=0 .
$$

The requirement for invertibility ${ }^{6}$ is that all the roots of $\xi(z)=0$ lie outside the unit circle. It follows that $\xi(z)>0$ when evaluated at $z=1$. But

$$
\xi(1)=\sum_{k=0}^{\infty} \xi_{k}, \text { so } \sum_{k=0}^{\infty} \xi_{k}>0 .
$$

5. Time variation in the standard deviation of $e$ is ruled out by the assumption that the log endowment is stationary. However, the model could be modified fairly easily to allow this standard deviation to vary through time, as long as it does so in a deterministic manner that is known to the representative agent. If the standard deviation varied stochastically, assumption 2 would be violated, and the model would become intractable.

6. Invertibility is a necessary and sufficient condition for the innovation in the Wold representation of a stationary time series to be interpretable as the difference between the current realization of the series and its best linear forecast conditional on lagged values of the series. This interpretation of the innovation $e$ is required for the analysis of the paper. 
Finally, the constant trend growth rate of the endowment is g.

(b) As an alternative to (a), one may assume that the first difference of the log endowment follows a univariate, stationary, invertible stochastic process with a constant drift. The unique invertible Wold representation for the change in the log endowment is written as

$$
\Delta \log c_{t}=g+\gamma(L) e_{t}=g+\sum_{k=0}^{\infty} \gamma_{k} e_{t-k},
$$

where, as before, $\gamma_{0}=1$ and $e_{t}$ is normally distributed with mean zero and standard deviation $s_{e}$. Stationarity and invertibility imply that

$$
\sum_{k=0}^{\infty} \gamma_{k}^{2}<\infty \text { and } \sum_{k=0}^{\infty} \gamma_{k}>0
$$

Equation (3) can be rewritten to express the level of the log endowment in terms of current and lagged innovations to the endowment growth rate. Adding $\log c_{t-1}$ to the left- and righthand sides of (3), and recursively substituting out $\log c_{t-i}$, $i=1,2,3, \ldots$, one obtains

$$
\begin{aligned}
\log c_{t}=g+\gamma_{0} e_{t}+g+\left(\gamma_{0}+\gamma_{1}\right) e_{t-1}+ & \ldots \\
& =g t+\sum_{k=0}^{\infty} \xi_{k} e_{t-k},
\end{aligned}
$$

where now $\xi_{i}=\sum_{k=0}^{i} \gamma_{k}$ so $\lim _{i \rightarrow \infty} \xi_{i}>0$ from invertibility of (3).

The two versions of assumption 3 incorporate (within the lognormal context) all the special cases studied in the existing literature. For example, LeRoy [1982] works with a two-state version of (a), and Michener [1982, 1984] presents AR(1) and AR(2) special cases of (a). Mehra and Prescott [1985] work with a two-state version of (b).

This paper will not be much concerned with the problem of existence of equilibrium. Its assumptions are essentially special versions of those made by Lucas [1978]. ${ }^{7}$ However, when the log endowment is nonstationary, it is important to check that expected utility is finite for any state of the system (history of log $c_{t}$ ). From equation (1) this requires that the growth rate of the

7. As Michener [1982] notes, however, the constant relative risk aversion utility function is not bounded, which violates one of Lucas' assumptions. 
expected utility of consumption at time $t+i$, not be faster than $1 / \beta$ in the limit as $i \rightarrow \infty$. The required condition is

$$
\lim _{i \rightarrow \infty} \frac{E_{t} c_{t+i}^{1-\alpha}}{E_{t} c_{t+i-1}^{1-\alpha}}<\frac{1}{\beta} .
$$

To evaluate the left-hand side of equation (5), I apply the wellknown formula for the expected value of a lognormal random variable: $\log E(X)=E(\log X)+(1 / 2) \operatorname{var}(\log X)$ when $X$ is $\log$ normal. This formula will be applied repeatedly in the course of the paper in solving for closed-form asset prices and returns. The limit is found to be $(1-\alpha) g$ in case (a), and

$$
(1-\alpha) g+\left(\frac{(1-\alpha)^{2}}{2}\right)\left[\sum_{k=0}^{\infty} \gamma_{k}\right]^{2} s_{e}^{2}
$$

in case (b). Thus, for expected utility to be finite, the mean rate of endowment growth cannot be too high and in the nonstationary case the sum of the $\gamma_{k}$ coefficients cannot be too large. Intuitively, the log endowment cannot be "too nonstationary."

\section{A Term Structure of Real Bonds}

In this section real discount bonds are priced from the firstorder conditions of the representative agent's maximization problem (1). The first-order condition for any asset is just that its marginal utility cost today equal the expected marginal utility of its future payoffs. For an $i$-period real discount bond, which $\operatorname{costs} P_{i t}$ units of the consumption good today and returns one unit of the good in period $t+i$,

$$
E_{t}\left[\beta^{i}\left(c_{t+i} / c_{t}\right)^{-\alpha}\right]=P_{i t}=\left(1+R_{i t}\right)^{-i},
$$

where $R_{i t}$ is the net return per period (or yield) on the $i$-period bond. The term in square brackets is conditionally lognormal, and thus one can apply the formula for the expected value of a lognormal random variable to obtain

$$
\begin{aligned}
i . \log \left(1+R_{i t}\right)= & i \cdot \log (1 / \beta)+\alpha E_{t}\left[\log c_{t+i}-\log c_{t}\right] \\
& -\left(\alpha^{2} / 2\right) \operatorname{var}_{t}\left[\log c_{t+i}-\log c_{t}\right] \\
= & i \cdot \log \left(\frac{1}{\beta}\right)+i \alpha g+\alpha\left[\sum_{k=0}^{\infty}\left(\xi_{k+i}-\xi_{k}\right) e_{t-k}\right] \\
& \quad-\left(\frac{\alpha^{2}}{2}\right)\left[\sum_{k=0}^{i-1} \xi_{k}^{2}\right] s_{e}^{2} .
\end{aligned}
$$


The first part of this equation is equivalent to expressions in Mankiw [1981], Hansen and Singleton [1983], and Breeden [1986]; the second part follows from the representation of consumption in equation (2).

For given $i$, the real interest rate on a real bond is inversely related to the discount factor $\beta$ and therefore positively related to the rate of time preference. The interest rate rises with the expected increase in log consumption from time $t$ to time $t+i$; this expected increase has trend and stochastic components.

The real interest rate on a real bond falls as the variance of the endowment shock increases. ${ }^{8}$ This can be explained as follows: Miller [1976] has shown that a sufficient condition for saving to increase with labor income uncertainty, in a multiperiod model with a known return to saving, is that $u^{\prime}(c)$ is positive and convex. The isoelastic utility function satisfies this condition. But the equilibrium interest rate is just that rate at which the agent is content to save exactly zero; therefore it falls with endowment uncertainty. ${ }^{9}$ Equivalently, note that the expected value of a convex function of a random argument increases with the variance of the argument: therefore the left-hand side of equation (6) increases with the variance of consumption, driving asset prices up and interest rates down. ${ }^{10}$

Risk premiums are most conveniently defined in this lognormal model to be the log of the ratio of expected gross returns on alternative investment strategies. These "log ratio" risk premiums are constant through time.

Defined this way, Campbell and Shiller's [1984] holding period premium on an $i$-period bond held for $j$ periods, over a $j$ period bond, is

$$
\begin{array}{r}
\phi_{i j t}=i \cdot \log \left(1+R_{i t}\right)+\log E_{t}\left[\left(1+R_{i-j, t+j}\right)^{-(i-j)}\right] \\
-j \cdot \log \left(1+R_{j t}\right) .
\end{array}
$$

Given $\phi_{i j t}$, it is trivial to obtain the conventional "difference" risk

8. This is a comparative static statement. The variance of the endowment was assumed to be constant through time in the derivation of (7).

9 . There are no income effects in this model to offset the substitution effect of a fall in the interest rate, because saving is zero in the model. In the standard two-period Fisher diagram, the budget line is rotated around the consumption point, not the intersection of the budget line with the horizontal (first-period) axis as in the standard experiment. Stiglitz [1970] presented a partial-equilibrium model of the term structure in which income and substitution effects offset each other. In general, he was unable to sign the combined result of these two effects.

10. See Breeden [1986] for further discussion of this effect. 
premium, the difference between expected $j$-period gross returns on $i$-period and $j$-period bonds, as

$$
\left(1+R_{j t}\right)^{j}\left(\exp \left[\phi_{i j t}\right]-1\right) .
$$

The difference risk premium varies in proportion with the gross $j$-period interest rate, and has the same sign as $\phi_{i j t}$, since gross interest rates are always positive.

Straightforward but tedious calculation shows that

$$
\phi_{i j t}=\alpha^{2}\left[\sum_{k=0}^{j-1} \xi_{k}\left(\xi_{k}-\xi_{i-j+k}\right)\right] s_{e}^{2} .
$$

Equation (8) expresses the holding premium as the product of three terms. Unsurprisingly, the premium is proportional to the variance of the innovation in the log endowment. It is proportional to the square of the coefficient of relative risk aversion, indicating that it is of second order for $\alpha$ close to zero, but is of first importance for large $\alpha$ values. ${ }^{11}$ Finally, the holding premium is proportional to a complicated function of the moving average parameters of the log endowment process.

In the special case of a unit holding period, (8) implies that

$$
\phi_{i 1 t}=\alpha^{2}\left[1-\xi_{i-1}\right] s_{e}^{2} .
$$

The one-period holding premium for an $i$-period bond is positive whenever $\xi_{i-1}<1$. The intuition behind this result is simple. When $\xi_{i-1}<1$, a positive endowment shock between $t$ and $t+1$ raises the $t+1$ endowment more than it raises the expected endowment at $t+i$ when the bond matures. Thus, a positive endowment shock lowers the yield on the bond and gives a capital gain to bondholders. Capital gains on such bonds are positively correlated with the ratio of consumption at $t+1$ to consumption at $t$, and negatively correlated with the corresponding ratio of marginal utilities. These bonds must therefore have a higher expected return at $t$.

In general, there will be some $i$ for which $\xi_{i}>1$, and thus some negative term premiums. ${ }^{12}$ But if the endowment is stationary, there is a presumption that term premiums are positive.

11. LeRoy [1983] notes an equivalent result in a two-state model.

12. LeRoy [1982] finds that term premiums are always positive in his model. This is because his model has only two states, so that if the state is currently good, it cannot improve further $(\xi<1$ for all $i)$. 
Since

$$
\sum_{i=0}^{\infty} \xi_{i}^{2}<\infty
$$

it must be the case that

$$
\lim _{n \rightarrow \infty} \sum_{i=0}^{n} \frac{\xi_{i}^{2}}{n}=0 \quad \text { and } \quad \lim _{i \rightarrow \infty} \xi_{i}=0 .
$$

The first limit implies that the proportion of maturities $i$ for which the square of $\xi_{i}$ exceeds unity, in a sample of the first $n$ maturities, must go to zero as $n \rightarrow \infty$. A fortiori the proportion of negative one-period holding premiums must go to zero. The second limit implies that one-period holding premiums approach

$$
\alpha^{2} s_{e}^{2} \quad \text { as } i \rightarrow \infty .
$$

Two simple examples of stationary stochastic processes for the log endowment may help to clarify the implications of the model. ${ }^{13}$ When the log endowment follows an AR(1) with parameter $a$ such that $-1<a<1$, then

$$
\xi_{i}=a^{i},
$$

and one-period holding premiums are always positive. They increase monotonically with maturity when $0<a<1$. When the log endowment follows an $\mathrm{AR}(2)$ with positive real roots, then output may have a "hump shape" [Blanchard, 1981], and there will be some negative one-period holding premiums at the short end of the term structure.

Figure I is a graphical illustration of the determination of one-period holding premiums in the stationary case. It displays a typical impulse response function, $\xi_{i}$ as a function of $i$, and the regions of negative and positive holding premiums. The slope of a line between the points $\left(0, \xi_{0}\right)$ and $\left(i-1, \xi_{i-1}\right)$ determines the response of the yield on an $i$-period bond to a unit positive innovation in the endowment. When this slope is positive, the holding premium is negative, and vice versa.

When the endowment is univariate stationary in first differences (version (b) of assumption 3), the formulas for risk premiums derived above are still valid. However, now $\xi_{i}$ is reinterpreted as the sum from 0 to $i$ of parameters $\gamma_{k}$. The $\gamma_{k}$ and not the $\xi_{i}$ have the stationarity properties.

13. These examples are studied in Michener [1982] and [1984], respectively. 


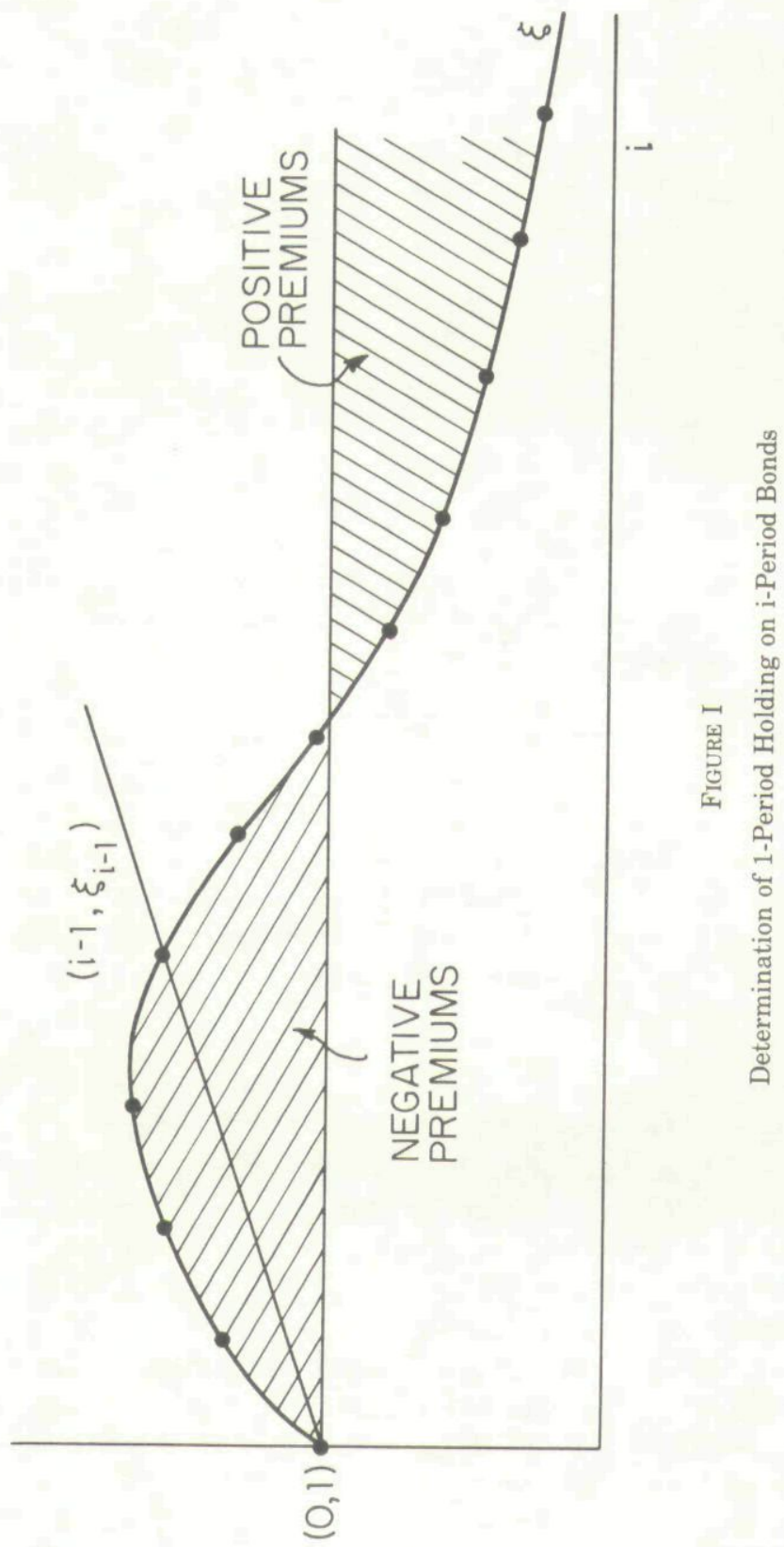


It is still the case that $\xi_{i}$ approaches some limit as $i \rightarrow \infty$, but from invertibility this limit is strictly greater than zero. If it is less than one, then premiums approach a positive limit that is strictly less than for the stationary case. This type of nonstationary process can be thought of as "mean-reverting" (even though its unconditional expectation is undefined), because some fraction of any shock is eventually offset. If $\lim \xi_{i}$ is greater than one, then term premiums approach a negative limit as $i$ increases. This type of nonstationary process is "mean-abandoning," in that the ultinate effect of any shock on the level of the endowment is greater than the initial impact. The borderline between these two types of nonstationary processes is the random walk, for which $\gamma_{0}=1$ and $\gamma_{k}=0$ for all $k>0$, so $\xi_{i}=1$ for all $i$. Here the ultimate effect of any shock equals the initial effect, and all term premiums are zero. (In fact, interest rates are nonstochastic, as can be seen from equation (7).)

The expected excess return on an $i$-period bond held to maturity, over a sequence of one-period bonds, is what Campbell and Shiller [1984] call the rolling premium. For the purposes of this model, it is written as

$$
\phi^{\prime}{ }_{i 1 t}=i \cdot \log \left(1+R_{i t}\right)-\log E_{t}\left[\left(1+R_{1 t}\right) \ldots\left(1+R_{1, t+i-1}\right)\right] .
$$

As in the case of the holding premium, the conventional "difference" rolling premium can be obtained from this and always has the same sign.

It turns out for the univariate case that

$$
\phi_{i 1 t}^{\prime}=\alpha^{2}\left[\sum_{k=0}^{i-1} \xi_{k}\left(1-\xi_{k}\right)\right] s_{e}^{2} .
$$

To understand the intuition of this result, consider the case where $i=2$. Then

$$
\phi_{21 t}^{\prime}=\alpha^{2}\left[\xi_{1}\left(1-\xi_{1}\right)\right] s_{e}^{2},
$$

where $\phi^{\prime}{ }_{21 t}$ can be negative if $\xi_{1}>1$, a case already discussed, or if $\xi_{1}$ is negative. To understand the latter condition, note that the return on a two-period rollover strategy is particularly high when short rates are higher than expected in period $t+1$. With $\xi_{1}<1$, this occurs when there is a negative endowment shock in period $t+1$. If $\xi_{1}$ is negative, the endowment will on average rebound to a higher level in period $t+2$ than the level that was expected in period $t$; thus, returns on the rollover strategy are positively 
correlated with the ratio of period $t+2$ consumption to period $t$ consumption, and must be higher on average than the returns on a "safe" strategy of holding a two-period bond for two periods. In other words, when $\xi_{1}$ is negative, the two-period bond has a negative risk premium. If $\xi_{1}$ is positive, however, a negative endowment shock at $t+1$ will tend to be followed by a lower endowment at $t+2$ than was originally expected, and the above conclusions are reversed.

A comparison of equations (9) and (11) shows that it is not possible to have a negative one-period holding premium and a positive rolling premium on a two-period bond. ${ }^{14}$ More generally, there is no presumption from stationarity alone that rolling premiums are positive. Under the strong condition that $0 \leqslant \xi_{i} \leqslant 1$, all $i$, rolling premiums are positive for all $i$ (as are all holding premiums).

\section{STOCKS}

I now consider the pricing of stocks, defined simply as (possibly levered) claims to a share of the random endowment at some period in the future ${ }^{15}$ The final payoff or dividend on a stock that matures at $t, d_{t}$, is specified as

$$
\log d_{t}=\eta \log c_{t} .
$$

Here $\eta$ measures the extent to which a stock is levered with respect to the endowment. A random payoff shock, uncorrelated with $\log c_{t}$, could be added to the right-hand side of (12); this would change the equilibrium prices of stocks but not their expected returns, so the formulas for risk premiums in this section would remain valid.

Define $P_{i t}^{*}$ as the real time $t$ price of an $i$-period stock. The real $\log$ return on the stock over $j$ periods, $j<i$, is $\log P_{i-j, t+j}^{*}$ $-\log P_{i t}^{*}$, and the real $\log$ return over $i$ periods is $\eta \log c_{t+i}$ $-\log P_{i t}^{*}=i \cdot \log \left(1+\mathrm{R}_{i t}^{*}\right)$.

Solve for the $i$-period log expected real return on an $i$-period stock:

14. This result was stressed by Woodward [1983]. Woodward used the terms "solidity premium" for minus the one-period holding premium on a two-period bond and "liquidity premium" for the rolling premium on a two-period bond.

15. I do not explicitly consider a more realistic "consol-like" stock, a claim to the whole stream of future endowments. The price of such a stock is the sum over $i$ of the prices $P^{*}$ in equation (18). Unfortunately, the formula for this price is messy, since the model generates simple solutions for log rather than natural prices. 


$$
\log E_{t}\left[\left(1+R_{i t}^{*}\right)^{i}\right]=i \cdot \log \left(1+R_{i t}\right)+\eta \alpha\left[\sum_{k=0}^{i-1} \xi_{k}^{2}\right] s_{e}^{2} .
$$

Over $i$ periods the real return on an $i$-period stock for $\eta>0$ is always expected to be higher than the real return on an $i$-period real bond. This result is unsurprising, since the payoff and therefore the return on the stock are perfectly positively correlated with consumption at time $t+i$. The difference between the log expected returns increases monotonically with maturity $i$. However, note that this "payoff uncertainty premium" is proportional only to $\alpha$ and not to $\alpha^{2}$ as is the real term premium.

Equation (7) showed that an increase in the variance of the endowment innovation lowers expected real bond returns. It lowers expected stock returns only if $\eta \alpha<\alpha^{2} / 2$; that is, if $\alpha>2 \eta$. For these high values of $\alpha$, the fall in the real bond return outweighs the increase in the payoff uncertainty premium.

Although for $\eta>0$ an $i$-period stock is always expected to yield more than an $i$-period real bond over $i$ periods, this result does not carry over to other holding periods or real bonds of other maturities. The expression for the $j$-period holding premium on an $i$-period stock, over a $j$-period real bond, is

$$
\phi_{i j t}^{*}=\phi_{i j t}+\eta \alpha\left[\sum_{k=0}^{j-1} \xi_{k} \xi_{i-j+k}\right] s_{e}^{2} .
$$

The $j$-period holding premium on an $i$-period stock is the sum of the $j$-period holding premium on an $i$-period real bond, and a term resulting from the payoff uncertainty on stocks. Neither term is unambiguously positive or negative in general. This illustrates the basic point that, for assets with a single payoff, payoff uncertainty translates directly into uncertainty about returns only when the holding period equals the maturity of an asset. Over other holding periods, an asset whose payoff is positively correlated with consumption may have a return that is negatively correlated with consumption and thus a negative holding premium.

Equation (14) may be used to determine the size of the "equity premium"- the expected one-period excess return on stock over a one-period real bond-for given parameters of the model. When $j=1$ and $\eta=1$, (14) simplifies to

$$
\phi_{i 1 t}^{*}=\left(\alpha^{2}\left[1-\xi_{i-1}\right]+\alpha \xi_{i-1}\right) s_{e}^{2} .
$$

The equity premium is the sum of two terms: a real term premium 
that is proportional to the square of $\alpha$ and falls with $\xi_{i-1}$, and a payoff uncertainty premium that is proportional to $\alpha$ and rises with $\xi_{i-1}$.

Mehra and Prescott [1985] have recently argued that historically observed equity premiums in the United States, on the order of 6 percent annually, are too high to be explained by a representative agent model with plausible parameter values. There are important differences between their model and the present one; notably, their model has only two states, and they price a more realistic "consol-like" stock rather than a single-payoff instrument. ${ }^{16}$ However the two models are sufficiently similar that a comparison is worthwhile.

Mehra and Prescott's consumption process is equivalent to an $\operatorname{ARIMA}(1,1,0)$ with negative serial correlation in log endowment changes. The serial correlation parameter is -0.14 , so

$$
\gamma_{i}=(-0.14)^{i} \text { and } \xi_{i}=\sum_{k=0}^{i} \gamma_{k} \lim _{i \rightarrow \infty} \xi_{i}=\frac{1}{1.14}=0.877 \text {. }
$$

For these parameter values, the limit as $i$ increases of the term in brackets multiplying the endowment innovation variance is 1 for $\alpha=1,2.25$ for $\alpha=2,5.48$ for $\alpha=4$, and 21.07 for $\alpha=10$, the largest $\alpha$ value considered to be plausible by Mehra and Prescott. Since the endowment innovation variance is only 0.00032 , the risk premium at $\alpha=10$ is only 0.0068 or 0.68 percent. This is larger than Mehra and Prescott's maximum value of 0.35 percent, but still in the same general area and much smaller than the observed equity premium.

These calculations are admittedly primitive, and may omit some important determinants of the measured equity premium. But the analytic formula (15) does clarify the reasons why a low equity premium is obtained from the estimated consumption process even at high $\alpha$ values. The limit of $\xi_{i-1}$ is close to 1 , so the term premium, proportional to the square of $\alpha$, is multiplied by a small number, while the payoff premium-proportional to $\alpha-$ is multiplied by a large one. If consumption were actually stationary around a deterministic trend, the limit of $\xi_{i-1}$ would be zero, and the equity premium would be five times larger at $\alpha=10$ (but smaller for $\alpha<1$ ).

16. One cost of greater realism in their notion of a stock is that Mehra and Prescott must solve for the equity premium numerically, rather than presenting a simple analytic formula as here. 


\section{TASTE SHOCKS}

In this Section I modify the basic model by introducing multiplicative "taste shocks" to the representative agent's utility function. There are two reasons why this is a worthwhile exercise.

First, in the traditional literature on the term structure,${ }^{17}$ it was sometimes asserted that investor preferences for consumption at a particular date would lower yields on bonds due to mature at that date, and furthermore would cause such bonds to have negative term premiums. The introduction of taste shocks brings the present model to bear on this question.

Second, there has recently been concern that econometric tests of the representative agent asset pricing framework, such as those of Hansen and Singleton [1982, 1983] are invalidated by taste shocks. Garber and King [1984] have argued this point with particular force. The estimates of the coefficient of relative risk aversion that are generated in the econometric literature are implausibly high (this is closely related to the equity premium puzzle discussed in the previous section). Introduction of taste shocks into the model of this paper allows one to see whether they have the effect of biasing upwards estimates of relative risk aversion which ignore taste shocks.

If multiplicative shocks $\lambda_{t}$ are added to the utility function, equation (1) becomes

$$
\max \sum_{i=0}^{\infty} \beta^{i} u\left(c_{t+i}\right)=\sum_{i=0}^{\infty} \beta^{i} \lambda_{t+i} \frac{c_{t+i}^{1-\alpha}}{1-\alpha} .
$$

The first-order condition for pricing a real discount bond, (6), becomes

$$
E_{t}\left[\beta^{i}\left(\lambda_{t+i} / \lambda_{t}\right)\left(c_{t+i} / c_{t}\right)^{-\alpha}\right]=P_{i t}=\left(1+R_{i t}\right)^{-i} .
$$

Note that when $\alpha=1$, that is, when the agent has a log utility function, taste shocks enter the first-order condition (17) in exactly the same way as endowment shocks. ${ }^{18}$

If taste shocks are to generate risk premiums in this model, they must be random and therefore contribute a conditional vari-

17. See, for example, Modigliani and Sutch [1966].

18. The effect of taste shocks should not be confused with the effect of a nongeometric discount function. The latter would cause expected changes through time in the relative valuation of consumption at two dates, and thus would generate a time inconsistency problem. Taste shocks, however, are indexed by time $t+i$ rather than by distance from the present time $i$, and so do not lead to time inconsistency. 
ance term to the formula for the interest rate. Suppose that the $\log$ of the taste parameter $\lambda_{t}$ follows a stationary stochastic process, in a manner analogous to the process for the endowment:

$$
\log \lambda_{t}=\sum_{k=0}^{\infty} \psi_{k} u_{t-k}
$$

As before, assume that $u_{t}$ is i.i.d. normal with mean zero and standard deviation $s_{u}$. For simplicity, assume that $u_{t}$ and $e_{t}$ are independent. Then the formula for the one-period holding premium on an $i$-period bond becomes

$$
\alpha^{2}\left[1-\xi_{i-1}\right] s_{e}^{2}+\left[1-\psi_{i-1}\right] s_{u}^{2},
$$

and similar terms are added to other risk premium concepts. However, the risk premiums on stocks over real bonds are not increased by taste shocks because stock payoffs are unaffected by these shocks.

An important feature of the taste-shock components of risk premiums is that they do not depend on the coefficient of relative risk aversion $\alpha$. By contrast with the endowment-shock components, they do not vanish as this coefficient goes to zero. Random preferences may generate predictable excess returns even when agents are risk neutral, which provides a counterexample to the traditional view that such premiums are zero under risk neutrality. ${ }^{19}$ The reason is that taste shocks cause randomness in the marginal utility of consumption (and therefore in interest rates), and premiums arise from randomness in marginal utility rather than from curvature of the utility function per se.

The taste shock components of one-period holding premiums may in general be positive or negative, but stationarity of taste shocks generates a presumption that they are positive. Thus, the analysis of both endowment shocks and taste shocks in the stationary case lends some support to Hicks's [1939] proposition that risk premiums on long bonds are positive.

The preceding analysis leads to the conjecture that taste shocks bias upwards estimates of $\alpha$ which ignore them, since they create risk premiums even when $\alpha=0$. This conjecture is correct as long as taste shocks and consumption levels are uncorrelated, but follow stochastic processes of similar form.

19. Cox, Ingersoll, and Ross [1981] provide an alternative counterexample in which interest rates are random because of shocks to the marginal productivity of capital. They also discuss deterministic preferences for consumption at one particular date, but do not consider random taste shocks. 
Suppose that an econometrician knows the values of $s_{e}$ and $\xi_{i-1}$ and estimates the square of $\alpha$ from the one-period holding premium on an $i$-period real bond as

$$
\phi_{i 1 t} /\left[1-\xi_{i-1}\right] s_{e}^{2} .
$$

From (19) this estimate equals

$$
\alpha^{2}+\left[1-\psi_{i-1}\right] s_{u}^{2} /\left[1-\xi_{i-1}\right] s_{e}^{2},
$$

which is greater than the square of $\alpha$ as long as $\psi_{i-1}$ and $\xi_{i-1}$ have the same sign. If both $c_{t}$ and $\lambda_{t}$ are stationary, the bias approaches the square of $s_{u} / s_{e}$ as $i$ increases. This is not very large for plausible values of $s_{u} / s_{e}$, but a much larger bias can be generated if taste shocks are close to white noise, while consumption is nonstationary and close to a random walk as in the model of Mehra and Prescott [1985].

The above analysis relies heavily on the assumption that taste shocks are uncorrelated with consumption levels. This assumption is not implausible in an exchange model with a nonstorable endowment, but it is unlikely to hold in a production model. When taste shocks are positively correlated with consumption, they may bias downwards estimates of $\alpha$ which ignore them. To see this, consider the case where $\alpha=1$ and $\lambda_{t}=c_{t}$. Then interest rates are nonrandom from (32), and there are no term premiums from (19), so an econometrician would estimate $\alpha=0$ which is below the true value. It remains to be seen whether a plausible taste shock process could explain the equity premium puzzle and the empirical results of Hansen and Singleton [1982, 1983].

\section{CONCLUSION}

In this paper I have presented a simple exchange model and discussed its implications for asset pricing. The model restricts the form of the representative agent's utility function and the distribution of shocks in a way that enables the derivation of closed-form solutions for asset prices and returns. In a significant generalization of previous work, the representative agent's endowment is modeled as a general univariate stochastic process, stationary and invertible in levels or first differences, rather than as a univariate Markov process. The further generalization to multivariate stationary processes is conceptually straightforward but is not undertaken here. 
The model sheds light on a number of issues. Some of the most important conclusions are the following:

1. The model shows under what conditions term premiums on long bonds are positive as conjectured by Hicks [1939]. When consumption is stationary, or follows a nonstationary process such that some fraction of any shock is eventually offset, then there is a presumption that one-period holding premiums on long bonds are positive. The premium on a bond of any particular maturity $i$ may be negative, but the limit as $i$ increases is positive.

2 . Stocks are not necessarily expected to yield more than real bonds except when both assets have the same maturity date and are held to maturity. In general, an asset with greater payoff uncertainty need not have greater uncertainty of return over some short holding period.

3 . The "equity premium" of stocks over a single-period riskless real rate can be decomposed into a component due to payoff uncertainty and proportional to the coefficient of relative risk aversion, and a term premium component that is proportional to the square of the coefficient of relative risk aversion. The relative weights of these two components depend on the stochastic process for consumption; for the process proposed by Mehra and Prescott [1985] to describe the U. S. economy, the former component dominates so that the equity premium does not increase rapidly with risk aversion.

5 . The model does not support the contention of Modigliani and Sutch [1966] that investor preferences for consumption at a particular date lower risk premiums on bonds maturing at that date. Random taste shocks do generate risk premiums, however; and as above, when taste shocks are stationary, there is a presumption that the premiums are positive for long bonds. This effect is independent of the agent's degree of relative risk aversion.

6 . Tests of the representative agent asset pricing framework are invalidated if there are aggregate taste shocks. Econometric estimates of the coefficient of relative risk aversion that ignore taste shocks are biased upwards if taste shocks and consumption levels are uncorrelated, but they may be biased downwards if there is positive correlation between taste shocks and consumption. 


\section{REFERENCES}

Blanchard, Olivier J., "What Is Left of the Multiplier-Accelerator?" American Economic Review, LXXI (1981), 150-54.

Breeden, Douglas T., "An Intertemporal Asset Pricing Model with Stochastic Consumption and Investment Opportunities," Journal of Financial Economics, VII (1979), 265-96.

, "Consumption, Production, Inflation and Interest Rates: A Synthesis," Journal of Financial Economics, XVI (1986), 3-40.

Campbell, John Y., and Robert J. Shiller, "A Simple Account of the Behavior of Long-Term Interest Rates," American Economic Review, LXXIV (1984), 44-48.

Cox, John C., Jonathan E., Ingersoll, Jr., and Stephen A. Ross, "A Re-examination of Traditional Hypotheses about the Term Structure of Interest Rates," Journal of Finance, XXXVI (1981), 769-99.

,$- \ldots$, and _ , "A Theory of the Term Structure of Interest Rates," Econometrica, LIII (1985), 385-408.

Donaldson, John B., and Rajnish Mehra, "Comparative Dynamics of an Equilibrium Intertemporal Asset Pricing Model," Review of Economic Studies, LI (1984), 491-508.

Eichenbaum, Martin S., Lars Peter Hansen, and Scott Richard, "The Dynamic Equilibrium Pricing of Durable Consumption Goods," unpublished paper, Carnegie-Mellon University, 1984.

Garber, Peter, and Robert King, "Deep Structural Excavation? A Critique of Euler Equation Methods," unpublished paper, University of Rochester, 1984.

Grossman, Sanford J., and Robert J. Shiller, "The Determinants of the Variability of Stock Market Prices," American Economic Review, LXXI (1981), 222-27.

Hansen, Lars Peter, and Kenneth J. Singleton, "Generalized Instrumental Variable Estimation of Nonlinear Rational Expectations Models," Econometrica, L (1982), 1029-54.

— , and - "Stochastic Consumption, Risk Aversion, and the Temporal Behavior of Ásset Returns," Journal of Political Economy, XCI (1983), 249-65.

Hicks, John R., Value and Capital: An Inquiry Into Some Fundamental Principles of Economic Theory (Oxford: Clarendon Press, 1939).

LeRoy, Stephen F., "Risk-Aversion and the Term Structure of Real Interest Rates," Economics Letters, X (1982), 355-62.

_ , "Risk-Aversion and the Term Structure of Real Interest Rates: Correction," Economics Letters, XII (1983), 339-40.

Lucas, Robert E., Jr., "Asset Prices in an Exchange Economy," Econometrica, XLVI (1978), 1429-45.

_, "Interest Rates and Currency Prices in a Two-Country World," Journal of Monetary Economics, X (1982), 335-59.

Mankiw, N. Gregory, "The Permanent Income Hypothesis and the Real Interest Rate," Economics Letters, VII (1981), 307-11.

Mehra, Rajnish, and Edward C. Prescott, "The Equity Premium: A Puzzle," Journal of Monetary Economics, XV (1985), 145-62.

Michener, Ronald W., "Variance Bounds in a Simple Model of Asset Pricing," Journal of Political Economy, XC (1982), 166-75.

_, "Permanent Income in General Equilibrium," Journal of Monetary Economics, XIII (1984), 297-305.

Miller, Bruce L., "The Effect on Optimal Consumption of Increased Uncertainty in Labor Income in the Multi-Period Case," Journal of Economic Theory, XIII (1976), 154-67.

Modigliani, Franco, and Richard Sutch, "Innovations in Interest Rate Policy," American Economic Review, LVI (1966), 178-97.

Nelson, Charles R., and Charles I. Plosser, "Trends and Random Walks in Macroeconomic Time Series: Some Evidence and Implications," Journal of Monetary Economics, X (1982), 139-62.

Stiglitz, Joseph E., "A Consumption-Oriented Theory of the Demand for Financial Assets and the Term Structure of Interest Rates," Review of Economic Studies, XXXVII (1970), 321-52.

Woodward, Susan, "The Liquidity Premium and the Solidity Premium," American Economic Review, LXXIII (1983), 348-61. 
Copyright of Quarterly Journal of Economics is the property of MIT Press and its content may not be copied or emailed to multiple sites or posted to a listserv without the copyright holder's express written permission. However, users may print, download, or email articles for individual use. 